\title{
Anatomi Laporan Keuangan Bank Bermasalah Sebelum Pencabutan Ijin Usaha
}

\author{
Hasan Ashari ${ }^{1 *}$, Trinandari P. Nugrahanti ${ }^{2}$ \\ 1, 2 Perbanas Institute Jakarta \\ 1ashar176@yahoo.com, ${ }^{2}$ trinandari@perbanas.id \\ ${ }^{*}$ Penulis korespondensi
}

\begin{abstract}
This research based on the many problematic rural banks (BPR) in Indonesia and had declared as failing banks those their business licenses had revoked by the bank supervisory authority. This paper aims to explain the conditions that occurred in the last years of a BPR before experiencing failure and to analyze the causes of this condition based on interviews with practitioners who had taken handle failed bank resolutions and references and financial indicators in the BPR. The bank condition is seen based on the financial reports for the last two years submitted by the BPR to the bank supervisory authority. This research was conducted by conducting interviews, studying literature, and analyzing the main financial ratios of banks by taking a sample of 31 rural banks whose business licenses had been revoked by the bank supervisory authority. The concluding of this study is mismanagement is the main factor that has impacted increasing of Non-Performing Loan (NPL), Operating Expense to Operating Income (OEOI), and Loan to Deposit Ratio (LDR), it Also has consistently decreasing Capital Adequacy Ratio (CAR) and Return on Asset (ROA).
\end{abstract}

Keywords: Management, Bank Failure, Bank Financial Ratios

\begin{abstract}
Abstrak
Penelitian ini didasari dengan banyaknya Bank Perkreditan Rakyat (BPR) di Indonesia yang bermasalah dan dinyatakan sebagai bank gagal sehingga dicabut izin usahanya oleh otoritas pengawas bank. Tulisan ini bertujuan menjelaskan kondisi yang terjadi di tahun-tahun terakhir BPR sebelum mengalami kegagalan dan menganalisis penyebab terjadinya kondisi dimaksud berdasarkan wawancara kepada praktisi yang berpengalaman menangani resolusi bank gagal dan referensi serta indikator keuangan yang ada di BPR. Kondisi bank dilihat berdasarkan laporan keuangan 2 (dua) tahun terakhir yang disampaikan BPR kepada otoritas pengawas bank. Penelitian ini dilakukan dengan melakukan wawancara, studi literatur dan menganalisis rasio-rasio keuangan utama bank dengan mengambil sampel 31 BPR yang telah dicabut izin usahanya oleh otoritas pengawas bank. Berdasarkan hasil penelitian ini disimpulkan bahwa kesalahan manajemen merupakan faktor utama yang menyebabkan terjadinya kredit macet (Non-performing Loan/NPL) dan mengakibatkan rasio keuangan lainnya seperti Beban Operasional pada Pendapatan Operasional (BOPO) dan rasio kredit terhadap Simpanan (Loan to Deposit Ratio/LDR) mengalami kenaikan sedangkan rasio Kecukupan Penyediaan Modal Minimum (KPMM) dan rasio laba terhadap aset (Return on Asset/ROA) mengalami penurunan secara konsisten.
\end{abstract}

Kata Kunci: Manajemen, Kegagalan Bank, Rasio Keuangan Bank 


\section{PENDAHULUAN}

Sesuai Undang-Undang No 7 tahun 1992 sebagaimana diubah dengan Undang-Undang Nomor 10 tahun 1998 tentang Perbankan, kategori bank di Indonesia terdiri dari bank umum (konvensional dan syariah) serta bank perkreditan rakyat/BPR (konvensional dan syariah). BPR ialah bank yang melakukan aktivitas usaha baik secara konvensional atau berdasarkan prinsip syariah dan tidak memberikan jasa dalam lalu lintas pembayaran. Aktivitas usaha BPR dibatasi pada: (1) penghimpunan dana masyarakat dalam simpanan berbentuk deposito berjangka, tabungan, dan/atau bentuk lainnya yang dipersamakan, (2) penyaluran kredit kepada nasabah, (3) pembiayaan dan penempatan dana berdasarkan Prinsip Syariah, sesuai dengan ketentuan yang ditetapkan oleh Bank Indonesia, (4) penempatan dana ke dalam Sertifikat Bank Indonesia (SBI), deposito berjangka, sertifikat deposito, dan atau tabungan pada bank lain. BPR merupakan salah satu commercialized institutional microfinance (usaha pembiayaan mikro komersial yang legal) yang dimaksudkan untuk mempercepat perkembangan ekonomi lokal dengan target rumah tangga berpenghasilan rendah dan usaha mikro dan kecil, sehingga diharapkan dapat melayani pangsa pasar khusus yang belum dapat dijangkau oleh bank umum (Hamada, 2010). Efisiensi dan kehati-hatian dalam kebijakan manajemen pada industri perbankan di Indonesia menjadi semakin penting dalam rangka meningkatkan kinerja BPR. BPR yang menjadi sumber utama dukungan bagi pengusaha kecil dan menengah harus menyempurnakan strategi manajemen bisnis termasuk yang terkait dengan fungsi intermediasi dan efisiensi bisnis (Chou \& Buchdadi, 2016).

Dalam rangka menjaga stabilitas keuangan dan pertumbuhan ekonomi yang lebih besar, BPR perlu memperkuat rasio modal, tata kelola ekuitas, meningkatkan etika dan budaya organisasi serta menekankan pada regulasi yang dapat menjaga likuiditas bank. Untuk meraih tujuan dimaksud dilakukan melalui dialog antara regulator dengan bank yang lebih intensif daripada sebatas pengawasan terhadap pelaksanaan ketentuan oleh pengawas bank. Hal-hal tersebut perlu terus dipertahankan sebagai cara untuk meningkatkan efektivitas tata kelola perusahaan dan regulasi yang berhati-hati (Thakor, 2020). Andriyan, Okky (2010) membuktikan bahwa kinerja keuangan perbankan dapat dipengaruhi oleh mekanisme tata kelola bank, bukan hanya sekedar pemenuhan ketentuan perbankan. Tata kelola BPR yang buruk memberikan peluang terjadinya pelanggaran etika dan merupakan penyebab utama terjadinya permasalahan di BPR. Kegagalan BPR telah berulang kali terjadi di Indonesia baik karena pelanggaran etika yang bersifat administratif maupun bukan administratif yang menjadi penyebab kuat terjadinya kegagalan bank (Ashari \& Nugrahanti, 2020), dalam kondisi krisis maupun normal yang disebabkan oleh hal-hal yang bersifat bisnis dan karena disebabkan adanya pelanggaran etika yang dilakukan oleh pemilik, pengurus, dan/atau pegawai bank (Sunardi \& Pradesa, 2019). Tingkat fraud yang terjadi sebelum bank dilikuidasi, dokumentasi dan aliran informasi dari laporan keuangan bank gagal merupakan hal-hal yang akan menjadi perhatian otoritas resolusi bank yaitu Lembaga Penjamin Simpanan (LPS) dalam melaksanakan likuidasi atas BPR yang dicabut ijin usahanya (Ashari \& Nugrahanti, 2018).

Berdasarkan data posisi 31 Desember 2019 terdapat 100 BPR yang telah dicabut ijin usahanya oleh OJK dan dilikuidasi oleh LPS. Penyebab utama banyaknya BPR yang dilikuidasi 
ialah karena memburuknya kinerja bank akibat adanya kecurangan (fraud) oleh pengurus bank, kejahatan yang dilakukan oleh pihak-pihak terkait dengan fraud, yaitu: penyalahgunaan/ pencurian dana/properti (34\%); pelanggaran kontrak (26\%); pembukuan melanggar hukum (26\%); penipuan/kecurangan (22\%); kesalahan penyajian (19\%); dan konspirasi jahat (15\%) dan alasan lainnya hingga 100\% (International Association of Deposit Insurers (IADI), 2006 dalam Ashari \& Nugrahanti, 2017). Terjadinya fraud dalam perbankan disebabkan oleh adanya tata kelola yang buruk yaitu praktik ketenagakerjaan yang buruk, kurang efektifnya pelatihan pegawai, staf yang kelebihan beban kerja, lemahnya sistem pengendalian internal, dan manajer bank dan pegawai yang rendah tingkat kepatuhannya (Bhasin, 2015). Manajemen perlu mengoperasikan suatu mekanisme kontrol yang menggabungkan langkah-langkah pencegahan sebelum adanya fraud. Pencegahan melalui aspek kualitatif dari pengendalian internal bank lebih diperlukan untuk mencegah fraud dibandingkan hanya melaksanakan banyak pengendalian anti-fraud, serta adanya risiko kegagalan dalam pengendalian manajemen adalah risiko yang lebih serius daripada kolusi pada bank (Suh \& Nicolaides, 2019). Sementara dalam penelitian lain dihasilkan bahwa suatu kebijakan manajemen risiko yang efektif untuk memberikan pedoman yang tepat atas perilaku tidak etis dan kegagalan bank perlu ditetapkan agar penambahan modal yang dilakukan pemilik bank guna memenuhi persyaratan modal minimum dan menjaga likuiditas dapat menghasilkan hasil positif untuk mencegah kegagalan bank (Mazhambe, 2016).

Terkait dengan indikator rasio keuangan, beberapa peneliti telah melakukan penelitian tentang penyebab kegagalan bank yang diindikasikan dengan rasio-rasio keuangan seperti NPL, LDR, ROA dan CAR, diantaranya Kangmartono et al. (2018) yang menyatakan bahwa kecukupan CAR dan kecukupan jumlah dewan komisaris berpengaruh positif signifikan terhadap kinerja keuangan BPR, Sofyan (2019) yang menyimpulkan bahwa tata kelola yang baik merupakan hal yang penting mengingat bahwa secara parsial CAR, LDR, dan BOPO berpengaruh negatif terhadap kinerja keuangan dalam hal ini adalah ROA, serta Sistiyarini \& Supriyono (2017) yang meneliti dan menyimpulkan bahwa variabel NPL, PDN, LDR, GCG, ROA dan NIM, dan CAR tidak berpengaruh terhadap kebangkrutan bank. Dari latar belakang tersebut, yang menjadi fokus permasalahan adalah (1) Apa Rasio yang yang pertama kali terdeteksi mengalami pemburukan di BPR? (2) Apa penyebab signifikan terjadinya kegagalan bank? (3) Kapan waktu terjadinya pemburukan kondisi BPR yang sesuai indikasi yang terungkap sesuai rasio yang ada?

Tujuan penelitian ini ialah untuk memberikan pemahaman kepada pembaca mengenai profil laporan keuangan bank yang mengalami permasalahan likuiditas dan solvabilitas sehingga dapat lebih berhati-hati dalam menempatkan dananya pada suatu bank. Sementara kepada praktisi BPR agar selalu menjaga prinsip perbankan yang sehat, segera melakukan deteksi dini (early warning) jika telah terjadi kondisi keuangan yang memerlukan perhatian segera. Selanjutnya manfaat kepada regulator agar dapat segera melakukan langkah-langkah yang tepat kepada BPR supaya tidak terjadi kegagalan bank. Penelitian ini juga diharapkan dapat melengkapi penelitian-penelitian terkait BPR yang ada sebelumnya, yaitu hal-hal terkait permasalahan/kegagalan BPR yang dicabut izin usahanya oleh pengawas bank yang belum dibahas di dalam penelitian sebelumnya, yaitu bagaimana tata kelola bank dapat 
mempengaruhi kondisi keuangan BPR dan bagaimana hubungannya dengan indikatorindikator seperti Capital Adequacy Ratio (CAR), Loan to Deposit Ratio (LDR), rasio Biaya Operasional dibandingkan dengan Pendapatan Operasional (BOPO) dan Return on Asset (ROA), dan bagaimana kegagalan tata kelola secara berurutan berimbas kepada indikator keuangan lainnya dan pada akhirnya menjadi penyebab terjadinya kegagalan BPR.

\section{METODE}

Penelitian ini merupakan penelitian kualitatif pada kasus yang bersifat khusus, laporan final disusun dalam struktur penulisan yang fleksibel (Creswell, 2009), mencakup serangkaian teknik interpretasi untuk mendeskripsikan kondisi yang terjadi pada kehidupan sosial (Cooper \& Schindler, 2006), berupaya memahami dan memberikan penafsiran kondisi yang ada sesuai dengan pemahaman masyarakat (Denzin \& Lincoln, 2005 dalam Wahyuni, 2015). Metode dalam penelitian ini adalah metode deskriptif, untuk menyelidiki keadaan, atau hal lain-lain yang sudah disebutkan, hasilnya dipaparkan dalam bentuk laporan (Arikunto, 1992), data dikumpulkan melalui survei angket, wawancara atau observasi (Sumanto, 2014).

Teknik pengambilan sampel atas data yang digunakan ialah teknik purposive sampling sehingga penentuan sampel dilakukan dengan pertimbangan tertentu. Kriteria yang ditetapkan oleh peneliti untuk informan dalam pengambilan sampel informan adalah praktisi yang berpengalaman menangani resolusi bank, sedangkan pertimbangan pengambilan data BPR likuidasi yang dijadikan sampel ialah BPR yang dicabut ijin usahanya pada 2010-2018, dan BPR yang memiliki paling kurang delapan kali laporan keuangan sebelum pencabutan ijin usaha untuk dapat dilakukan analisis.

Sumber data dalam penelitian ini diperoleh dari data primer dan sekunder. Data primer melalui wawancara singkat terhadap praktisi yang pernah menangani proses resolusi bank gagal secara sampel dan data sekunder dalam bentuk data bank gagal dari situs otoritas resolusi bank https://lps.go.id dan laporan keuangan bank dari situs otoritas pengawas bank htpps://ojk.go.id, jurnal ilmiah terkait perbankan baik di Indonesia maupun negara lain, media massa, dan lainnya yang terkait dengan tema yang dibahas yang diperoleh peneliti secara tidak langsung atau melalui dokumen (Sugiyono, 2013).

\section{HASIL DAN PEMBAHASAN}

Data primer diperoleh penulis dari kuesioner yang disampaikan penulis melalui pesan singkat kepada praktisi yang menangani resolusi bank. Kuesioner tersebut menggali informasi terkait penyebab menurunnya tingkat kesehatan bank yang dapat menyebabkan kegagalan bank. Praktisi dalam hal ini adalah pegawai LPS yang melakukan penanganan bank bermasalah dimulai saat dilakukannya pemeriksaan bank oleh LPS pada masa bank status dalam pengawasaan khusus sampai dengan proses likuidasi bank. Dari pertanyaan yang diberikan penulis menerima 10 jawaban hasil kuesioner. Berdasarkan hasil survei diperoleh data informan sebagai berikut: 
Tabel 1 Profil Informan

\begin{tabular}{clc}
\hline Kriteria & \multicolumn{1}{c}{ Uraian } & Frek \\
\hline Masa Kerja & 0 s.d. 7 tahun & 0 \\
& 7 s.d. 10 tahun & 4 \\
& Lebih dari 10 tahun & 6 \\
\hline \multirow{2}{*}{ Jabatan } & Kepala Divisi & 8 \\
& Pelaksana & 2 \\
\hline \multirow{2}{*}{ Bidang Kerja } & Pemeriksaan Bank & 2 \\
& Penanganan Klaim & 2 \\
& Pelaksanaan Resolusi Bank & 2 \\
& Likuidasi Bank & 1 \\
& Analisis Metode Resolusi & 1 \\
& Surveilan & 1 \\
& Penanganan Premi & 1 \\
\hline
\end{tabular}

Sumber: Diolah Penulis

Sesuai profil informan pada tabel 1, penulis memandang bahwa praktisi yang menjadi informan dalam penelitian ini memiliki kompetensi dan kapabilitas yang memadai sehingga layak dijadikan informan dalam penelitian ini. Terkait dengan kuesioner penulis menyampaikan kuesioner untuk meminta pendapat praktisi mengenai indikator mana dari lima indikator tingkat kesehatan BPR yaitu: (1) permodalan, (2) kualitas aktiva produktif, (3) manajemen, (4) rentabilitas, dan (5) likuiditas, yang merupakan penyebab utama terjadinya kegagalan bank. Informan memilih angka 1 (satu) s.d. 5 (lima), dengan satu untuk bobot penyebab kegagalan bank paling rendah dan lima paling tinggi. Sesuai jawaban hasil kuesioner, diperoleh informasi bahwa bobot yang paling tinggi adalah faktor "Manajemen" dengan bobot rata-rata 4,2. Hasil jawaban selengkapnya pada tabel 2 berikut:

Tabel 2 Indikator Kesehatan Bank dengan Bobot Penyebab Kegagalan Tertinggi

\begin{tabular}{clcc}
\hline No & \multicolumn{1}{c}{ Faktor } & Bobot & Urutan \\
\hline 1 & Manajemen & 4,2 & 1 \\
2 & Kualitas aktiva produktif & 3,6 & 2 \\
3 & Permodalan & 3,5 & 3 \\
4 & Likuiditas & 3,4 & 4 \\
5 & Rentabilitas & 2,5 & 5 \\
\hline
\end{tabular}

Sumber: Diolah Penulis

Sedangkan data sekunder dalam penelitian ini adalah data 31 BPR yang telah dilikuidasi dari 100 Bank Dalam Likuidasi (BDL) sampai dengan posisi 31 Desember 2019 (LPS, 2020) atau sebesar 31\% dari sampel. Data sampel yang dipilih merupakan BPR yang memiliki laporan keuangan sesuai kebutuhan penelitian ini yaitu 8 (delapan) laporan keuangan periodik triwulanan sebelum BPR dicabut ijin usahanya. Jika sampel dibagi berdasarkan kategori permodalan terdiri dari: (1) Buku 1= 17 BPR (55\%) (2) Buku 
2= 13 BPR (42\%) dan (3) Buku 3= 1 (satu) BPR (3\%). Selengkapnya sebagaimana tabel 3 berikut:

Tabel 3 Sampel BPR yang di Cabut Izin Usahanya (CIU)

\begin{tabular}{|c|c|c|c|c|c|}
\hline & Nama BPR & Kategori & Tanggal CIU & Lap. Terakhir & $\begin{array}{c}\text { Jangka } \\
\text { waktu } \\
\text { (Bulan) }\end{array}$ \\
\hline (a) & (b) & (c) & (d) & (e) & $f=(e-d)$ \\
\hline 1 & PT BPR Dhasatra Artha Sempurna & Buku 1 & $3 / 2 / 2017$ & $1 / 12 / 2016$ & 2 \\
\hline 2 & PT BPR Akarumi & Buku 1 & $25 / 04 / 2018$ & $1 / 3 / 2018$ & 2 \\
\hline 3 & $\begin{array}{l}\text { PT BPR Cakra Dharma } \\
\text { Arthamandiri }\end{array}$ & Buku 1 & $20 / 11 / 2017$ & $1 / 9 / 2017$ & 3 \\
\hline 4 & PT BPR Bungo Mandiri & Buku 1 & $8 / 12 / 2014$ & $1 / 9 / 2014$ & 3 \\
\hline 5 & PT BPR Mega Karsa Mandiri & Buku 1 & $5 / 6 / 2018$ & $1 / 3 / 2018$ & 3 \\
\hline 6 & BPR LPN Kampung Manggis & Buku 1 & $29 / 11 / 2017$ & $1 / 9 / 2017$ & 3 \\
\hline 7 & PT BPR Budisetia & Buku 1 & $25 / 05 / 2018$ & $1 / 3 / 2018$ & 3 \\
\hline 8 & PT BPR Nusa Galang Makmur & Buku 1 & $7 / 3 / 2017$ & $1 / 12 / 2016$ & 3 \\
\hline 9 & PT BPR Mustika Utama Kolaka & Buku 1 & $20 / 06 / 2016$ & $1 / 3 / 2016$ & 4 \\
\hline 10 & PT BPR Cinere Artha Raya & Buku 1 & $6 / 11 / 2013$ & $1 / 6 / 2013$ & 5 \\
\hline 11 & PT BPR Sisibahari Dana & Buku 1 & $5 / 9 / 2017$ & $1 / 3 / 2017$ & 6 \\
\hline 12 & $\begin{array}{l}\text { PT BPR Kampung Baru Muaro } \\
\text { Paiti }\end{array}$ & Buku 1 & $2 / 3 / 2015$ & $1 / 9 / 2014$ & 6 \\
\hline 13 & PT BPR Tugu Kencana & Buku 1 & $16 / 04 / 2014$ & $1 / 9 / 2013$ & 8 \\
\hline 14 & PT BPR Arthasraya Sejahtera & Buku 1 & $20 / 06 / 2014$ & $1 / 9 / 2013$ & 10 \\
\hline 15 & PT BPR Carano Nagari & Buku 1 & $10 / 7 / 2015$ & $1 / 9 / 2014$ & 10 \\
\hline 16 & PT BPR Sukowati Jaya & Buku 1 & $23 / 01 / 2013$ & $1 / 12 / 2011$ & 14 \\
\hline 17 & PT BPR Sinar Baru Perkasa & Buku 1 & $6 / 12 / 2017$ & $1 / 9 / 2014$ & 40 \\
\hline 18 & PT BPR KS Bali Agung Sedana & Buku 2 & $3 / 11 / 2017$ & $1 / 6 / 2017$ & 5 \\
\hline 19 & PT BPR Mutiara Artha Pratama & Buku 2 & $23 / 12 / 2013$ & $1 / 9 / 2013$ & 4 \\
\hline 20 & PT BPR Sambas Arta & Buku 2 & $12 / 7 / 2018$ & $1 / 3 / 2018$ & 4 \\
\hline 21 & PT BPR Indomitra Mega Kapital & Buku 2 & $15 / 06 / 2017$ & $1 / 3 / 2017$ & 4 \\
\hline 22 & PT BPR Mitra Danagung & Buku 2 & $24 / 09 / 2013$ & $1 / 6 / 2013$ & 4 \\
\hline 23 & PT BPR Vox Modern Danamitra & Buku 2 & $29 / 01 / 2014$ & $1 / 9 / 2013$ & 5 \\
\hline 24 & PT BPR Lumasindo Perkasa Putra & Buku 2 & $7 / 2 / 2014$ & $1 / 9 / 2013$ & 5 \\
\hline 25 & PT BPR Kujang Artha Sembada & Buku 2 & $14 / 11 / 2013$ & $1 / 6 / 2013$ & 6 \\
\hline 26 & PT BPR Bina Dian Citra & Buku 2 & $4 / 4 / 2018$ & $1 / 9 / 2017$ & 7 \\
\hline 27 & PT BPR Berok Gunung Pangilun & Buku 2 & $5 / 4 / 2013$ & $1 / 9 / 2012$ & 7 \\
\hline 28 & PT BPR Dana Niaga Mandiri & Buku 2 & $13 / 04 / 2016$ & $1 / 9 / 2014$ & 20 \\
\hline
\end{tabular}




\begin{tabular}{c|c|c|c|c|c}
\hline & Nama BPR & Kategori & Tanggal CIU & Lap. Terakhir & $\begin{array}{c}\text { Jangka } \\
\text { waktu } \\
\text { (Bulan) }\end{array}$ \\
\hline (a) & (b) & (c) & (d) & (e) & f=(e-d) \\
\hline 29 & PT BPR Kudamas Sentosa & Buku 2 & $29 / 04 / 2016$ & $1 / 6 / 2014$ & 23 \\
30 & PT BPR Artha Dharma & Buku 2 & $15 / 08 / 2016$ & $1 / 9 / 2014$ & 24 \\
31 & PT BPR Agra Arthaka Mulya & Buku 3 & $14 / 01 / 2016$ & $1 / 9 / 2014$ & 17 \\
\hline
\end{tabular}

Sumber: Otoritas Jasa Keuangan (2019)

Dari tabel 3, jangka waktu antara laporan terakhir (yang merupakan laporan sebelum/ pada saat bank masuk status dalam pengawasan khusus/DPK) dengan pencabutan izin usaha (CIU) paling cepat adalah 2 (dua) bulan dan paling lama adalah 40 bulan. Rata-rata jangka waktu pencabutan izin usaha sejak laporan keuangan terakhir yang disampaikan BPR kepada OJK adalah 5 (lima) bulan (dengan mengeluarkan enam sampel yang outlier). Pada tabel 4 berikut ditemukan bahwa jangka waktu mayoritas BPR kurang dari 6 bulan (65\%).

Tabel 4 Jangka Waktu Laporan Keuangan Terakhir dengan Tanggal CIU

\begin{tabular}{clcc}
\hline No & Selisih Waktu (Bulan) & Jumlah BPR & \% \\
\hline 1 & Selisih $\leq 3$ bulan & 8 & $26 \%$ \\
2 & $3<$ Selisih $\leq 6$ bulan & 12 & $39 \%$ \\
3 & $6<$ Selisih $\leq 9$ bulan & 3 & $10 \%$ \\
4 & $9<$ Selisih $\leq 12$ bulan & 2 & $6 \%$ \\
5 & $12<$ Selisih $\leq 24$ bulan & 5 & $16 \%$ \\
6 & Selisih $>24$ bulan & 1 & $3 \%$ \\
\hline & Jumlah & 31 & $100 \%$ \\
\hline
\end{tabular}

Sumber: Diolah Penulis

Terjadinya jangka waktu yang relatif lama yakni lebih dari 6 (enam) bulan pada 35\% BPR tersebut, karena pemilik BPR tidak berhasil menyehatkan kembali BPR melalui merger atau menyuntikkan tambahan modal untuk memperkuat permodalan bank. Kegagalan untuk merger atau menambah modal berakibat bank menjadi bank gagal dan pada akhirnya dilakukan pencabutan ijin usaha bank. Ketidakcukupan modal akan menyebabkan bank menderita kegagalan karena tidak memiliki kemampuan untuk memenuhi kewajibannya kepada nasabah dan/atau kreditornya. Hal ini sesuai pengertian bank gagal menurut Federal Deposit Insurance Corporation (FDIC, 2014) dan Thomson (1991) adalah bank yang telah mengalami kebangkrutan, kegagalan ekonomi karena ketidakcukupan modal dan gagal untuk memenuhi kewajibannya. 


\section{Perbandingan Hasil Wawancara dengan Literatur terkait}

Tata kelola perusahaan yang baik menurut Peraturan Otoritas Jasa Keuangan Nomor 4/POJK 03/2015 tentang Penerapan Tata Kelola bagi Bank Perkreditan Rakyat yang diberlakukan sejak tanggal 1 April 2015 adalah tata kelola bank yang menerapkan prinsipprinsip keterbukaan (transparency), akuntabilitas (accountability), pertanggungjawaban (responsibility), profesional (professional), dan kewajaran (fairness). Pengawas bank secara rutin menilai tingkat kesehatan BPR dengan berpedoman kepada surat keputusan Direksi Bank Indonesia No. 30/12/Kep/DIR tanggal 30 April 1997. Penilaian kesehatan BPR diukur dengan menggunakan parameter penilaian faktor-faktor: (1) permodalan, (2) kualitas aktiva produktif, (3) manajemen, (4) rentabilitas, dan (5) likuiditas.

Sesuai informasi kualitatif yang diperoleh dari praktisi pada tabel 2 diperoleh bahwa faktor manajemen adalah faktor pertama yang menyebabkan kegagalan bank (bobot 4,2 dari skala 5). Berdasarkan informasi dari situs OJK yang diakses pada tanggal 12 Agustus 2020, penulis memperoleh 20 dokumen Siaran Pers dari OJK sejak tahun 2017 sampai dengan tahun 2019 terkait dengan pencabutan izin usaha BPR. Dari siaran pers tersebut diperoleh informasi bahwa kelemahan pengelolaan BPR oleh manajemen menduduki peringkat pertama yaitu berjumlah 17 dari 20 BPR atau 85\%.

Selain siaran pers tersebut, sesuai literatur yang ada juga diperoleh informasi bahwa (1) manajemen yang tidak efisien dan Non-Performing Loan dapat merusak stabilitas industri perbankan (Uche, 2015), (2) risiko kegagalan dalam pengendalian manajemen adalah risiko yang lebih serius daripada kolusi pada bank (Suh \& Nicolaides, 2019). (3) terjadinya fraud dalam perbankan disebabkan oleh adanya praktik ketenagakerjaan yang buruk, kurang efektifnya pelatihan pegawai, staf yang kelebihan beban kerja, lemahnya sistem pengendalian internal, dan manajer bank dan pegawai yang rendah tingkat kepatuhannya (Bhasin, 2015). Urutan penyebab kegagalan BPR tercantum pada tabel 5 berikut ini.

Tabel 5 Penyebab Kegagalan BPR

\begin{tabular}{lcc}
\hline \multicolumn{1}{c}{ Penyebab Kegagalan BPR } & Frek & \% \\
\hline $\begin{array}{l}\text { 1. Kelemahan pengelolaan BPR oleh manajemen } \\
\text { 2. BPR tidak mampu memperbaiki kinerja keuangan sesuai standar yang } \\
\text { ditetapkan }\end{array}$ & 17 & $85 \%$ \\
$\begin{array}{l}\text { 3. Praktik perbankan yang tidak sehat baik oleh Pengurus maupun } \\
\text { Pemegang Saham }\end{array}$ & 1 & $10 \%$ \\
\hline Jumlah & 20 & $100 \%$ \\
\hline
\end{tabular}

Sumber: Diolah Penulis

\section{Perbandingan Hasil Wawancara dengan Rasio Keuangan}

Untuk membuktikan faktor manajemen merupakan faktor utama yang menyebabkan kegagalan bank, penulis mencoba menggali informasi dari data rasio keuangan yang diperoleh dari 31 BPR yang dicabut ijin usahanya untuk menjawab pertanyaan bagaimana 
kesalahan manajemen dapat merusak kinerja keuangan BPR dan pada akhirnya menyebabkan kegagalan BPR, dan rasio keuangan mana yang pertama kali menunjukan adanya kesalahan manajerial yang dilakukan oleh manajemen BPR.

Data rasio keuangan yang digunakan untuk digunakan dalam penelitian ini adalah: NPL, KPMM, ROA, LDR dan BOPO. Pada tabel 6 berikut, penulis merangkum data rata-rata rasio keuangan dimaksud yang diperoleh dari 8 (delapan) laporan keuangan akhir 31 BPR sebelum dicabut izin usahanya.

Tabel 6 Analisis Rasio Laporan Keuangan (dalam \%)

\begin{tabular}{rrrrrrrrrr}
\hline \multirow{2}{*}{ No } & Rasio & \multicolumn{4}{c}{ Laporan (n) Bulan dari Laporan Terakhir/Masa DPI } & \multicolumn{2}{c}{$\begin{array}{c}\text { Laporan } \\
\text { Terakhir/DPK }\end{array}$} \\
\cline { 3 - 8 } & & $\mathbf{2 1}$ & $\mathbf{1 8}$ & $\mathbf{1 5}$ & $\mathbf{1 2}$ & $\mathbf{9}$ & $\mathbf{6}$ & $\mathbf{3}$ & Terakn \\
\hline 1 & NPL & 10,60 & 10,95 & 11,85 & 14,55 & 15,04 & 16,70 & 20,61 & 24,35 \\
2 & ROA & 46 & -7 & -91 & -93 & -190 & -288 & -557 & -753 \\
3 & BOPO & 118 & 128 & 141 & 148 & 149 & 224 & 262 & 307 \\
4 & LDR & 78,00 & 77,35 & 79,77 & 82,12 & 85,61 & 88,10 & 96,38 & 108,31 \\
5 & KPMM & 15,31 & 12,19 & 13,79 & 14,78 & 11,22 & 8,96 & 4,11 & $-10,32$ \\
\hline
\end{tabular}

Sumber: Diolah Penulis

Sesuai tabel 6, secara umum ditemukan bahwa sejak 2 (dua) tahun atau 21 bulan sebelum laporan keuangan terakhir rata-rata semua rasio keuangan tidak memenuhi standar ketentuan perbankan, yaitu: (1) NPL dan BOPO mengalami kenaikan terus menerus secara konsisten, dengan puncaknya pada laporan terakhir rata-rata NPL lebih dari $24 \%$ dan BOPO lebih dari 300\%, (2) ROA mengalami penurunan bahkan negatif sejak 18 bulan sebelum laporan terakhir, (3) KPMM dan LDR menunjukkan kondisi memburuk menjelang akhir-akhir masa DPI/awal DPK hingga pada akhirnya KPMM menjadi negatif dan LDR naik lebih dari $100 \%$ saat laporan terakhir.

\section{Rasio Kredit Macet (Non-Performing Loan/NPL)}

Menurut Kasmir (2015), Non-Perfoming Loan (NPL) ialah salah satu risiko yang muncul karena semakin kompleksnya kegiatan perbankan, semakin besar NPL maka semakin besar risiko kredit yang dihadapi. Menurut SE BI Nomor 13/24/DPNP tanggal 25 Oktober 2011, standar NPL yang sehat jika jumlah kredit bermasalah tidak lebih dari 5\% dari total kredit yang diberikan kepada debitor. Pada tabel 7 berikut diketahui Rata-rata NPL BPR secara konsisten mengalami kenaikan, dengan rata-rata Kenaikan NPL tertinggi terjadi pada 12 bulan dan 3 bulan sebelum laporan terakhir bank masingmasing 22,78\% dan 23,41\%. Kenaikan NPL dimaksud menunjukkan risiko kredit semakin besar melebihi standar NPL yang sehat sebagaimana SE BI Nomor 13/24/DPNP tanggal 25 Oktober 2011. 
Tabel 7 Rata-rata NPL

\begin{tabular}{ccc}
\hline $\begin{array}{c}\text { Tahun Akhir/Bulan Ke-n } \\
\text { Sebelum Lap. Terakhir }\end{array}$ & $\begin{array}{c}\text { \% } \\
\text { NPL }\end{array}$ & \% Naik/turun \\
\hline 21 & 10,60 & - \\
18 & 10,95 & 3.30 \\
15 & 11,85 & 8.22 \\
12 & 14,55 & 22.78 \\
9 & 15,04 & 3.37 \\
6 & 16,70 & 11.04 \\
3 & 20,61 & 23.41 \\
Lap. Terakhir & 24,35 & 18.15 \\
\hline
\end{tabular}

Sumber: Diolah Penulis

Sesuai literatur yang ada, penyebab NPL tidak memenuhi standar adalah: (1) adanya kredit macet yang diberikan kepada eksekutif puncak dan debitor berulang (Mazhambe, 2016), (2) adanya kredit fiktif, (Sunardi \& Pradesa, 2019). Kredit macet dan kredit fiktif tersebut terjadi karena adanya praktik perbankan yang tidak sehat, pengelolaan manajemen risiko yang lemah, tata kelola perusahaan yang buruk dan fraud atau penggelapan oleh manajemen (Ashari \& Nugrahanti, 2017).

Berdasarkan tabel 8 berikut ini, jika dianalisis lebih lanjut sesuai klasifikasi jenis Buku BPR, tidak ada perbedaan signifikan antara NPL berdasarkan klasifikasi modal BPR di laporan terakhir/masa Dalam Pengawasan Khusus (DPK) dibandingkan laporan pada 2 (dua) tahun terakhir/pada masa Dalam Pengawasan Intensif (DPI), yaitu rasio NPL mayoritas masing-masing Buku 2 dan Buku 1 BPR sudah lebih dari 5\%. Pada laporan terakhir sebelum pencabutan ijin usaha (CIU) hanya 4 (empat) BPR dengan NPL kurang dari 5\% sisanya 27 BPR lebih dari 5\%, dari sebelumnya 23 BPR di atas 5\% dan 8 (delapan) BPR di bawah 5\%.

Tabel 8 Rata-rata NPL Perbandingan Tahun-Tahun Akhir dengan Laporan Keuangan Terakhir

\begin{tabular}{llcccccccc}
\hline & & \multicolumn{3}{c}{ Tahun akhir \& Masa DPI } & \multicolumn{3}{c}{ Laporan Keu. Terakhir/DPK } \\
\cline { 3 - 9 } No & Uraian & Buku & Buku & Buku & Total & Buku & Buku & Buku & Total \\
& & $\mathbf{1}$ & $\mathbf{2}$ & $\mathbf{3}$ & $\mathbf{1}$ & $\mathbf{2}$ & $\mathbf{3}$ & 1 \\
\hline 1 & NPL $<2 \%$ & 1 & 1 & 0 & 2 & 0 & 1 & 0 & 1 \\
2 & $2 \% \leq$ NPL $<5 \%$ & 1 & 4 & 1 & 6 & 2 & 1 & 0 & 3 \\
3 & $5 \% \leq$ NPL $<8 \%$ & 1 & 1 & 0 & 2 & 1 & 0 & 0 & 1 \\
4 & $8 \% \leq$ NPL 12\% & 6 & 0 & 0 & 6 & 0 & 1 & 1 & 2 \\
5 & NPL $\geq 12 \%$ & 8 & 7 & 0 & 15 & 14 & 10 & 0 & 24 \\
\hline & Total & 17 & 13 & 1 & 31 & 17 & 13 & 1 & 31 \\
\hline
\end{tabular}

Sumber: Diolah Penulis

Menurut hasil wawancara, hal berikutnya yang perlu diperhatikan setelah faktor manajemen adalah kualitas aktiva produktif yaitu suatu kondisi yang menunjukkan 
kemampuan BPR dalam menyediakan dana (dalam mata uang rupiah) dalam rangka memperoleh pendapatan setelah memperhitungkan Penyisihan Penghapusan Aktiva Produktif (PPAP) sesuai Peraturan Otoritas Jasa Keuangan Republik Indonesia Nomor 33 /POJK.03/2018 yang ditetapkan pada tanggal 27 Desember 2018 Tentang Kualitas Aset Produktif dan Pembentukan Penyisihan Penghapusan Aset Produktif Bank Perkreditan Rakyat.

Semakin tinggi NPL atau kredit macet akan membuat PPAP yang akan dibentuk lebih tinggi sehingga kualitas aktiva produktif menjadi menurun/semakin rendah. Dampak yang ditimbulkan dari adanya Non-Perfoming Loan (NPL) yang tidak wajar adalah hilangnya kesempatan memperoleh pendapatan dari kredit yang diberikan, sehingga mengurangi perolehan laba dan berpengaruh buruk bagi profitabilitas bank dalam hal ini ROA dan ROE.

\section{Rasio Laba terhadap Aset (Return on Asset/ROA)}

Menurut SE BI Nomor 13/24/DPNP tanggal 25 Oktober 2011 standar ROA yang ditetapkan untuk bank-bank di Indonesia adalah minimal 1,5\%. Rata-rata ROA secara konsisten mengalami penurunan pada bulan ke-18 (pertama kali bernilai negatif) sebelum laporan terakhir dengan rata-rata penurunan tertinggi yaitu $1220 \%$ pada 15 bulan sebelum pencabutan ijin usaha dilakukan oleh OJK. Selengkapnya pada tabel 9 berikut.

Tabel 9 ROA

\begin{tabular}{ccc}
\hline $\begin{array}{c}\text { Tahun Akhir/Bulan Ke-n } \\
\text { Sebelum Lap Terakhir }\end{array}$ & $\begin{array}{c}\text { \% } \\
\text { ROA }\end{array}$ & \% Naik/turun \\
\hline 21 & 46 & - \\
18 & -7 & $-1,15$ \\
15 & -91 & $-12,20$ \\
12 & -93 & $-0,02$ \\
9 & -190 & $-1,04$ \\
6 & -288 & $-0,52$ \\
3 & -557 & $-0,93$ \\
Lap. Terakhir & -753 & $-0,35$ \\
\hline
\end{tabular}

Sumber: Diolah Penulis

ROA bernilai negatif merupakan akibat adanya NPL yang tidak wajar. Kredit yang diberikan tidak seluruhnya menghasilkan pendapatan karena adanya nasabah yang tidak dapat membayar angsuran pokok dan/atau bunga kredit, sehingga mengurangi perolehan laba dan akhirnya berpengaruh buruk bagi profitabilitas bank. Dari tabel 7 dan tabel 9 dapat dilihat bahwa profitabilitas bank dalam hal ini ROA akan tergantung pada besar kecilnya kredit bermasalah/NPL yang dihadapi oleh pihak bank. Semakin tinggi kenaikan NPL maka ROA akan semakin menurun dengan angka terakhir NPL sebesar 24,35\% menyebabkan ROA turun menjadi $-753 \%$. 
Berdasarkan tabel 10 berikut ini, jika dianalisis lebih lanjut sesuai klasifikasi modal/ Buku BPR, tidak ada perbedaan signifikan antara ROA berdasarkan klasifikasi modal BPR di laporan terakhir dibandingkan laporan pada 2 (dua) tahun akhir/pada masa DPI, rasio ROA mayoritas masing-masing Buku 2 dan Buku 1 BPR sudah $\leq 0 \%$.

Tabel 10 Perbandingan ROA Tahun-Tahun Akhir dengan Laporan Keuangan Terakhir

\begin{tabular}{|c|c|c|c|c|c|c|c|c|c|}
\hline \multirow[b]{2}{*}{ No } & \multirow[b]{2}{*}{ Uraian } & \multicolumn{4}{|c|}{ Tahun akhir \& Masa DPI } & \multicolumn{4}{|c|}{ Laporan Keu. Terakhir/DPK } \\
\hline & & $\begin{array}{c}\text { Buku } \\
1\end{array}$ & $\begin{array}{c}\text { Buku } \\
2\end{array}$ & $\begin{array}{c}\text { Buku } \\
3\end{array}$ & Total & $\begin{array}{c}\text { Buku } \\
1\end{array}$ & $\begin{array}{c}\text { Buku } \\
2\end{array}$ & $\begin{array}{c}\text { Buku } \\
3\end{array}$ & Total \\
\hline 1 & $\mathrm{ROA} \leq 0 \%$ & 12 & 9 & 0 & 21 & 14 & 10 & 0 & 24 \\
\hline 2 & $0 \%<\mathrm{ROA} \leq 0,5 \%$ & 2 & 1 & 0 & 3 & 0 & 0 & 0 & 0 \\
\hline 3 & $0,5 \%<\mathrm{ROA} \leq 1,25 \%$ & 0 & 1 & 0 & 1 & 0 & 0 & 0 & 0 \\
\hline 4 & $1.25 \%<\mathrm{ROA} \leq 1,5 \%$ & 1 & 0 & 0 & 1 & 1 & 0 & 0 & 1 \\
\hline 5 & $\mathrm{ROA}>1,5 \%$ & 2 & 2 & 1 & 5 & 2 & 3 & 1 & 6 \\
\hline & Total & 17 & 13 & 1 & 31 & 17 & 13 & 1 & 31 \\
\hline
\end{tabular}

Sumber: Diolah Penulis

\section{Rasio Beban Operasional pada Pendapatan Operasional (BOPO)}

Rasio BOPO merupakan rasio antara biaya yang dikeluarkan oleh bank dalam menjalankan aktivitas utamanya terhadap pendapatan yang diperoleh dari aktivitas tersebut. Semakin kecil rasio BOPO menunjukkan semakin efisien suatu bank dalam menjalankan aktivitas usahanya. Perhitungan rasio BOPO menurut SE BI No. 6/23/DPNP tanggal 31 Mei 2004, Bank Indonesia menetapkan angka terbaik untuk rasio BOPO adalah di bawah 90\%, karena jika rasio BOPO melebihi 90\% hingga mendekati angka 100\%, bank tersebut dapat dikategorikan tidak efisien dalam menjalankan operasinya. Pada tabel 11, Rasio BOPO menunjukkan BPR semakin tidak efisien dalam menjalankan aktivitas usahanya karena sudah melebihi rasio BOPO menurut SE No. 6/23/DPNP tanggal 31 Mei 2004 yaitu di bawah 90\%. Kondisi rata-rata BOPO BPR secara konsisten mengalami kenaikan sejak 18 bulan sebelum laporan terakhir dengan kenaikan rata-rata BOPO tertinggi terjadi terjadi pada 6 (enam) bulan sebelum laporan terakhir yaitu $50 \%$.

Tabel 11 Rata-rata BOPO

\begin{tabular}{ccc}
\hline $\begin{array}{c}\text { Tahun Akhir/Bulan Ke-n } \\
\text { Sebelum Lap Terakhir }\end{array}$ & \% BOPO & $\begin{array}{c}\text { \% Naik/ } \\
\text { turun }\end{array}$ \\
\hline 21 & 118 & - \\
18 & 128 & 8.47 \\
15 & 141 & 10.16 \\
12 & 148 & 4.96 \\
9 & 149 & 0.68 \\
6 & 224 & 50.34 \\
3 & 262 & 16.96 \\
Lap. Terakhir & 307 & 17.18 \\
\hline
\end{tabular}

Sumber: Diolah Penulis 
Kenaikan BOPO menunjukan pendapatan operasional berupa bunga yang diperoleh dari penempatan dana dalam bentuk kredit dan pendapatan operasi lainnya mengalami penurunan sedangkan biaya yang dikeluarkan oleh bank dalam menjalankan aktivitas utamanya seperti biaya bunga, biaya tenaga kerja, biaya pemasaran dan biaya operasi lainnya relatif tetap. Kredit yang diberikan tidak menghasilkan pendapatan karena nasabah tidak dapat membayar angsuran pokok dan atau bunga kredit, sehingga mengurangi perolehan laba dan berpengaruh buruk bagi profitabilitas bank. Dari tabel 9 dan tabel 11 dapat dilihat bahwa BOPO akan tergantung pada besar kecilnya ROA yang diterima oleh pihak bank. Semakin tinggi penurunan ROA maka BOPO akan semakin tinggi dengan angka terakhir ROA sebesar -753\% menyebabkan BOPO menjadi 307\%.

Jika dianalisis lebih lanjut sesuai klasifikasi jenis Buku BPR, tidak ada perbedaan signifikan antara BOPO berdasarkan klasifikasi modal BPR di laporan terakhir dibandingkan laporan pada 2 (dua) tahun akhir/pada masa BDPI, rasio BOPO mayoritas masing-masing Buku 2 dan Buku 1 BPR mencapai > 100\%. Informasi tersebut disajikan pada tabel 12.

Tabel 12 Perbandingan BOPO Tahun-Tahun Akhir dengan Laporan Keuangan Terakhir

\begin{tabular}{|c|c|c|c|c|c|c|c|c|c|}
\hline \multirow[b]{2}{*}{ No } & \multirow[b]{2}{*}{ Uraian } & \multicolumn{4}{|c|}{ Tahun akhir \& Masa DPI } & \multicolumn{4}{|c|}{ Laporan Keu. Terakhir/DPK } \\
\hline & & $\begin{array}{c}\text { Buku } \\
1\end{array}$ & $\begin{array}{c}\text { Buku } \\
2\end{array}$ & $\begin{array}{c}\text { Buku } \\
3\end{array}$ & Total & $\begin{array}{c}\text { Buku } \\
1\end{array}$ & $\begin{array}{c}\text { Buku } \\
2\end{array}$ & $\begin{array}{c}\text { Buku } \\
3\end{array}$ & Total \\
\hline 1 & BOPO $\leq 0 \%$ & 0 & 0 & 0 & 0 & 2 & 1 & 0 & 3 \\
\hline 2 & $0<\mathrm{BOPO} \leq 85 \%$ & 0 & 2 & 1 & 3 & 1 & 1 & 1 & 3 \\
\hline 3 & $85 \%<\mathrm{BOPO} \leq 100 \%$ & 2 & 0 & 0 & 2 & 1 & 1 & 0 & 2 \\
\hline 4 & $100 \%<$ BOPO $\leq 150 \%$ & 5 & 7 & 0 & 12 & 1 & 3 & 0 & 4 \\
\hline 5 & $150 \%<\mathrm{BOPO} \leq 200 \%$ & 3 & 2 & 0 & 5 & 3 & 3 & 0 & 6 \\
\hline 6 & BOPO > 200\% & 7 & 2 & 0 & 9 & 9 & 4 & 0 & 13 \\
\hline & Total & 17 & 13 & 1 & 31 & 17 & 13 & 1 & 31 \\
\hline
\end{tabular}

Sumber: Diolah Penulis

\section{Rasio Kredit terhadap Simpanan (Loan to Deposit Rasio)}

Loan to Deposits Ratio (LDR) merupakan rasio perbandingan antara jumlah dana yang disalurkan ke masyarakat (kredit) dengan jumlah dana masyarakat dan modal sendiri yang digunakan (Kasmir, 2015). Toleransi Loan to Deposits Ratio (LDR) menurut SE BI Nomor 13/24/DPNP tanggal 25 Oktober 2011 standar untuk nilai Loan to Deposit Ratio (LDR) adalah sebesar 78\%-100\%. Pada tabel 13 terlihat bahwa rata-rata rasio LDR bank telah memenuhi SE BI Nomor 13/24/DPNP tersebut. Rata-rata LDR secara konsisten mengalami kenaikan sejak 15 bulan sebelum Laporan Terakhir, dengan rata-rata kenaikan LDR tertinggi terjadi pada 3 bulan sebelum laporan terakhir dan Laporan terakhir sebelum bank di cabut ijin usahanya, masing-masing 9,34\% dan 12,38\%. 
Tabel 13 Rata-rata LDR

\begin{tabular}{ccc}
\hline $\begin{array}{c}\text { Tahun Akhir/Bulan Ke-n } \\
\text { Sebelum Lap Terakhir }\end{array}$ & $\begin{array}{c}\text { \% } \\
\text { LDR }\end{array}$ & \% Naik/turun \\
\hline 21 & 78,00 & - \\
18 & 77,35 & -0.83 \\
15 & 79,77 & 3.13 \\
12 & 82,12 & 2.95 \\
9 & 85,61 & 4.25 \\
6 & 88,15 & 2.97 \\
3 & 96,38 & 9.34 \\
Laporan Terakhir & 108,31 & 12.38 \\
\hline
\end{tabular}

Sumber: Diolah Penulis

Bila di analisis lebih lanjut berdasarkan klasifikasi asset BPR berdasarkan tabel 14 berikut, kondisi LDR BPR pada tahun akhir dan masa DPI ditemukan bahwa hanya 16 BPR dengan LDR yang memenuhi standar toleransi menurut SE BI Nomor 13/24/DPNP tanggal 25 Oktober 2011 yaitu sebesar 78\%-100\%. Sisanya 15 BPR tidak optimal atau melebihi toleransi. Sedangkan pada laporan terakhir sebelum CIU hanya 10 BPR yang relatif optimal $78 \%<$ LDR $\leq 100 \%$ sisanya 21 BPR tidak optimal atau melebihi toleransi.

Tabel 14 Perbandingan LDR Tahun Akhir dengan Laporan Keuangan Terakhir

\begin{tabular}{cccccccccc}
\hline & \multirow{2}{*}{ No } & Uraian & \multicolumn{3}{c}{ Tahun akhir \& Masa DPI } & \multicolumn{3}{c}{ Laporan Keu. Terakhir/DPK } \\
\cline { 2 - 10 } & & Buku 1 & Buku 2 & Buku 3 & Total & Buku 1 & Buku 2 & Buku 3 & Total \\
\hline 1 & LDR $\leq 78 \%$ & 6 & 3 & 0 & 9 & 6 & 1 & 0 & 7 \\
2 & $78 \%<$ LDR $\leq 85 \%$ & 4 & 2 & 0 & 6 & 1 & 2 & 0 & 3 \\
3 & $85 \%<$ LDR $\leq 100 \%$ & 2 & 7 & 1 & 10 & 1 & 5 & 1 & 7 \\
4 & $100 \%<$ LDR $\leq 120 \%$ & 5 & 1 & 0 & 6 & 4 & 1 & 0 & 5 \\
5 & LDR $>120 \%$ & 0 & 0 & 0 & 0 & 5 & 4 & 0 & 9 \\
\hline & Total & 17 & 13 & 1 & 31 & 17 & 13 & 1 & 31 \\
\hline
\end{tabular}

Sumber: Diolah Penulis

Rasio LDR yang melebihi ketentuan regulasi dalam hal ini lebih dari 100\% pada laporan keuangan terakhir merupakan indikasi adanya kredit fiktif atau kredit macet yang belum dilunasi oleh debitor atau terdapat dana pihak ketiga (DPK) yang semakin berkurang seiring penarikan dana oleh nasabah penyimpan. Sedangkan yang kurang dari 78\% mengindikasikan adanya fraud atas kas, dana yang seharusnya disalurkan kepada nasabah dalam bentuk kredit tidak terlaksana.

\section{Rasio Kecukupan Penyediaan Modal Minimum (KPMM)}

Pasal 2 Peraturan Otoritas Jasa Keuangan Nomor 5/POJK.03/2015 tanggal 31 Maret 2015 tentang Kewajiban Penyediaan Modal Minimum dan Pemenuhan Modal Mnimum Bank 
Perkreditan Rakyat bahwa BPR wajib menyediakan modal minimum sebesar 12\% dari aktiva tertimbang menurut risiko. Pada tabel 15 berikut, secara umum KPMM BPR sampai dengan bulan ke-12 masih memenuhi Nomor 5/POJK.03/2015 tanggal 31 Maret 2015 dimaksud.

Tabel 15 Rata-rata KPMM

\begin{tabular}{ccc}
\hline $\begin{array}{c}\text { Tahun Akhir/Bulan Ke-n } \\
\text { Sebelum Lap Terakhir }\end{array}$ & $\begin{array}{c}\text { \% } \\
\text { KPMM }\end{array}$ & \% Naik/turun \\
\hline 21 & 15,31 & - \\
18 & 12,19 & -20.3 \\
15 & 13,79 & 13.13 \\
12 & 14,78 & 7.18 \\
9 & 11,22 & -24.09 \\
6 & 8,96 & -20.14 \\
3 & 4,11 & -54.13 \\
Lap. Terakhir & $-10,32$ & -351.09 \\
\hline
\end{tabular}

Sumber: Diolah Penulis

Rata-rata KPMM secara konsisten mengalami penurunan sejak 9 (sembilan) bulan sebelum Laporan Terakhir Penurunan dengan rata-rata penurunan KPMM tertinggi terjadi pada Laporan terakhir sebelum bank di cabut ijin usahanya, masing-masing $-54.13 \%$ dan $351.09 \%$.

KPMM pada tahun akhir dan masa DPI, hanya 18 BPR dengan KPMM yang di bawah $12 \%$ sisanya 19 BPR sama atau di atas $12 \%$. Sedangkan pada laporan terakhir sebelum CIU hanya 9 (sembilan) BPR di atas 12\%, sisanya 22 BPR di bawah 12\%. Sedangkan pada laporan terakhir/Masa DPK sebelum CIU sebanyak 24 BPR memiliki KPMM negatif, dan hanya 7 (tujuh) BPR yang positif. Terjadi penurunan signifikan modal BPR di tahun akhir dan masa DPI. Informasi tersebut disajikan pada tabel 16 berikut.

Tabel 16 Perbandingan KPMM Tahun-Tahun Akhir dengan Laporan Keuangan Terakhir

\begin{tabular}{|c|c|c|c|c|c|c|c|c|c|}
\hline \multirow[b]{2}{*}{ No } & \multirow[b]{2}{*}{ Uraian } & \multicolumn{4}{|c|}{ Tahun akhir \& Masa DPI } & \multicolumn{4}{|c|}{ Laporan Keu. Terakhir/DPK } \\
\hline & & $\begin{array}{c}\text { Buku } \\
1\end{array}$ & $\begin{array}{c}\text { Buku } \\
2\end{array}$ & $\begin{array}{c}\text { Buku } \\
3\end{array}$ & Total & $\begin{array}{c}\text { Buku } \\
1\end{array}$ & $\begin{array}{c}\text { Buku } \\
2\end{array}$ & $\begin{array}{c}\text { Buku } \\
3\end{array}$ & Total \\
\hline 1 & KPMM $<0 \%$ & 4 & 2 & 0 & 6 & 9 & 6 & 0 & 15 \\
\hline 2 & $0 \% \leq \mathrm{KPMM}<6 \%$ & 1 & 2 & 0 & 3 & 0 & 1 & 0 & 1 \\
\hline 3 & $6 \% \leq \mathrm{KPMM}<8 \%$ & 0 & 0 & 0 & 0 & 2 & 1 & 0 & 3 \\
\hline 4 & $8 \% \leq \mathrm{KPMM}<9 \%$ & 1 & 3 & 0 & 4 & 0 & 0 & 0 & 0 \\
\hline 5 & $9 \% \leq \mathrm{KPMM}<12 \%$ & 4 & 0 & 1 & 5 & 1 & 1 & 1 & 3 \\
\hline 6 & $\mathrm{KPMM} \geq 12 \%$ & 7 & 6 & 0 & 13 & 5 & 4 & 0 & 9 \\
\hline & Total & 17 & 13 & 1 & 31 & 17 & 13 & 1 & 31 \\
\hline
\end{tabular}

Sumber: Diolah Penulis

Terkait dengan pemenuhan kecukupan permodalan bagi bank yang mengalami permasalahan solvabilitas dan masuk dalam status pengawasan khusus (DPK), Otoritas 
Pengawas Bank mengambil beberapa tindakan di antaranya memerintahkan bank dan/atau shareholders menyampaikan proposal perbaikan atas permodalan, melaksanakan kewajiban dalam melakukan aktivitas perbaikan, dan aktivitas lainnya seperti penggantian komisaris dan/atau direksi bank, menghapusbukuan kredit macet dan mengkompensasi kerugian yang terjadi ke dalam modal bank, merger atau konsolidasi dengan bank lain. Apabila dalam jangka waktu 3 (tiga) bulan tidak terlaksana maka otoritas pengawas bank akan menyerahkan bank bermasalah kepada otoritas resolusi bank yang dalam hal ini Lembaga Penjamin Simpanan guna mengambil keputusan untuk menyelamatkan (penempatan modal sementara/LPS) atau likuidasi (Ashari \& Nugrahanti, 2017).

Apabila pemegang saham ingin menyelamatkan bank, maka pemegang saham perlu menetapkan suatu kebijakan manajemen risiko yang efektif dalam rangka memberikan pedoman yang tepat terkait perilaku tidak etis perlu ditetapkan agar penambahan modal yang dilakukan pemilik bank untuk memenuhi persyaratan modal minimum dan menjaga likuiditas dapat menghasilkan hasil positif untuk mencegah kegagalan bank (Mazhambe, 2016).

\section{SIMPULAN}

Dalam tulisan ini dapat disimpulkan bahwa permasalahan tata kelola manajerial yang terjadi membuat BPR salah urus sehingga terjadilah fraud atau salah kelola yang berakibat terjadinya kredit macet (NPL tinggi). NPL yang tinggi tersebut menyebabkan turunnya pendapatan bank karena tidak adanya pendapatan bunga dan pengembalian angsuran pokok kredit yang berakibat keringnya likuiditas BPR dengan indikasi meningkatnya rasio BOPO dan menurunnya rasio ROA. Bila kekeringan likuiditas akibat kredit macet terus terjadi dan berlarut-larut penyelesaiannya maka dapat menyebabkan meningkatnya penyisihan aktiva produktif dan semakin memperkecil profitabilitas BPR bahkan dapat menyebabkan kerugian BPR. Kerugian BPR selanjutnya akan menggerus modal sehingga bank akan mengalami permasalahan solvabilitas/permodalan. Permasalahan solvabilitas yang tak terselesaikan secara internal oleh bank akan membuat bank dimasukkan dalam status pengawasan intensif atau pengawasan khusus oleh otoritas pengawas bank/0JK. Jika dalam batas waktu yang ditetapkan oleh OJK juga tidak dapat terselesaikan, maka bank dinyatakan sebagai bank gagal dan dicabut ijin usahanya oleh OJK.

Keterbatasan dalam penelitian ini adalah ialah penulisan ini menggunakan sampel laporan keuangan 31 bank dari 100 BPR yang dicabut izin usahanya oleh OJK/BI sampai dengan 31 Desember 2019 karena adanya keterbatasan kelengkapan data laporan keuangan BPR yang diperoleh di situs OJK. Untuk penulisan pada masa yang akan datang diharapkan lebih banyak sampel yang didapatkan dalam penelitian sehingga analisis yang dilakukan lebih akurat lagi. Saran penulis dalam hal ini kepada BPR adalah agar dapat menaati seluruh ketentuan perbankan khususnya terkait mengenai Peraturan Otoritas Jasa Keuangan (POJK) Nomor 4/POJK 03/2015 tentang Penerapan Tata Kelola bagi Bank Perkreditan Rakyat. Sementara saran penulis kepada OJK selaku pengawas bank adalah agar dapat meningkatkan pembinaan dan pengawasan kepada BPR dalam hal ini khususnya pelaksanaan Peraturan Otoritas Jasa Keuangan (POJK) Nomor 4/POJK 03/2015 tentang Penerapan Tata Kelola bagi Bank Perkreditan Rakyat. 


\section{PUSTAKA ACUAN}

Andriyan, Okky, dan S. (2010). Pengaruh Mekanisme Corporate Governance Terhadap Kinerja Keuangan Bank Perkreditan Rakyat. Jurnal Akuntansi Dan Keuangan Indonesia, 7(2), 187-204. http://jaki.ui.ac.id/index.php/home/article/view/163

Arikunto, S. (1992). Prosedur Penelitian. Jakarta: Rineka Cipta.

Ashari, Hasan., and Nugrahanti, T. P. (2017). Implication of Liquidation Method to Recovery Rate and Residual Asset: The Case of Rural Banks in Indonesia. Scientific Journal of PPI-UKM, 4(1), 43-54. https://doi.org/10.27512/sjppi-ukm/ses/a15012018

Ashari, H., \& Nugrahanti, T. P. (2018). Metode Likuidasi Bank pada Bank Perkreditan Rakyat. JURNAL RISET AKUNTANSI \& KEUANGAN, 6(3), 333-348. http://ejournal.upi. edu/index.php/JRAK/article/view/4670

Ashari, H., \& Nugrahanti, T. P. (2020). Apakah Pelanggaran Etika Menjadi Penyebab Terjadinya Fraud Dan Kegagalan Bank Perkreditan Rakyat (BPR)? Neraca Keuangan, 15(2). doi: http://dx.doi.org/10.32832/neraca.v15i2.3497

Bhasin, M. L. (2015). Menace of Frauds in the Indian Banking Industry: An Empirical Study. SSRN Electronic Journal, 4(12), 1-13. https://doi.org/10.2139/ssrn.2676466

Chou, T.-K., \& Buchdadi, A. D. (2016). Bank Performance and Its Underlying Factors: A Study of Rural Banks in Indonesia. Accounting and Finance Research, 5(3), 55-63. https://doi.org/10.5430/afr.v5n3p55

Cooper, D.R., \& Schindler, P. S. (2006). Business Research Methods (Eleventh E). McGraw Hill.

Creswell, J. . (2009). Research Design: Qualitative, Quantitative, and Mixed Methods Approach (Ed, 3rd). Sage Publication. url:http://search.ebscohost.com/login. aspx?direct=true \&db=psyh\&AN=2008-13604-000\&site=ehost-live \&scope=site

Denzin, N. K., \& Lincoln, Y. S. (2005). Introduction: The Discipline and Practice of Qualitative Research (T. S. handbook of qualitative Research (ed.); In N. K. D). Sage Publications Ltd.

FDIC. (2014). FEDERAL DEPOSIT INSURANCE CORPORATION. https://www.fdic.gov/about/ strategic-plans/performance/2014annualplan.pdf

Hamada, M. (2010). Commercialization of microfinance in indonesia: The shortage of funds and the linkage program. Developing Economies, 48(1), 156-176. https://doi. org/10.1111/j.1746-1049.2010.00102.x

International Association of Deposit Insurers (IADI). (2006). General Guidance for the Resolution of Bank Failures. In The Research and Guidance Committee International Association of Deposit Insurers Working Paper.

Kangmartono, B. G. H. (2018). Pengaruh Mekanisme Corporate Governance Terhadap Indonesia. Jurnal Wawasan Manajemen, 6, 101-114.

Kasmir. (2015). Manajemen Perbankan. Jakarta: PT RajaGrafindo Persada. PERS.

Mazhambe, C. (2016). Corporate Governance and Business Ethics Structural Failures for Kingdom Bank Africa Limited (KBAL) Botswana. British Journal of Economics, Management \& Trade, 13(2), 1-6. https://doi.org/10.9734/bjemt/2016/19852 
Sistiyarini, E., \& Supriyono, S. E. (2017). the Application of Risk Based Bank Rating on Bankruptcy Prediction of Banks in Indonesia. Jurnal Keuangan Dan Perbankan, 21(2), 302-311. https://doi.org/10.26905/jkdp.v21i2.564

Sofyan, M. (2019). Faktor-Faktor Yang Mempengaruhi Profitabilitas Bank Perkreditan Rakyat (BPR) di Provinsi Jawa Timur. Jurnal Inspirasi Bisnis Dan Manajemen, 3(1), 63-76. https://doi.org/doi.org/10.33603/jibm.v3i1.2093

Sugiyono. (2013). Metode Penelitian Manajemen. Alfa Beta.

Suh, JB.; Nicolaides, R. (2019). The effects of reducing opportunity and fraud risk factors on the occurrence of occupational fraud in financial institutions. International Journal of Law, Crime and Justice, 56(march), 79-88. https://doi.org/10.1016/j.ijlcj.2019.01.002

Sumanto. (2014). Teori dan Aplikasi Metode Penelitian. CAPS.

Sunardi, S., \& Pradesa, H. A. (2019). An empirical evidence of ethical climate index in rural banks from Board of Directors Perspective. Journal of Economics, Business \& Accountancy Ventura, 21(3), 373. https://doi.org/10.14414/jebav.v21i3.1590

Thakor, A. V. (2020). Ethics, Culture and Higher Purpose in Banking: Post-Crisis Governance Developments. March 14. http://dx.doi.org/10.2139/ssrn.3554121

Thomson, J. B. (1991). Predicting Bank Failures in the 1980s. Economic Review, 17(1). https://doi.org/Federal Reserve Bank of Cleveland

Uche, O. B. (2015). The Relationship between Liquidation and Banking Industry Stability in Nigeria. Dr. Onwe Basil Uche Department of Banking and Finance, Faculty of Management Sciences Ebonyi State University, Abakaliki - Nigeria. International Journal of Small Business and Entrepreneurship Research, 3(7), 88-99.

Wahyuni, S. (2015). Qualitative Research Method-Theory and Practice (Second Edi). Jakarta: Salemba Empat Publisher. https://scholar.ui.ac.id/en/publications/qualitative-researchmethod-theory-and-practice-2nd-edition

Laporan tahunan LPS tahun 2019 (2020) di pada situs https://www.lps.go.id/laporantahunan diakses 12 Agustus 2020.

Laporan Keuangan BPR di https://www.ojk.go.id/id/kanal/perbankan/data-dan-statistik/ laporan-keuangan-perbankan/default.asp x diakses 12 September 2019

Siaran Pers di https://www.ojk.go.id/id/kanal/perbankan/berita-dan-kegiatan/siaran-pers/ Default.aspx diakses 12 Agustus 2020 